\title{
Lactic Acid Bacteria from Honey Bees Digestive Tract and Their Potential as Probiotics
}

\author{
Nurdjannah Jane Niode ${ }^{1,2^{*}}$, Christina L Salaki ${ }^{1}$, Laurentius J M Rumokoy ${ }^{1}$, Trina \\ Ekawati Tallei ${ }^{1,3}$ \\ ${ }^{1}$ Entomology Study Program, Postgraduate Program, Sam Ratulangi University, North Sulawesi 95115, Indonesia \\ ${ }^{2}$ Department of Dermatology and Venereology, Faculty of Medicine, Sam Ratulangi University/RD Kandou Hospital, \\ Manado, North Sulawesi 95115, Indonesia \\ ${ }^{3}$ Department of Biology, Faculty of Mathematics and Natural Sciences, Sam Ratulangi University, North Sulawesi \\ 95115, Indonesia \\ *Corresponding author. Email: niodejane@unsrat.ac.id
}

\begin{abstract}
Honey bees (Apis spp.) are social insects that possess unique gut microbiota community. There are three main phyla that dominate the honey bees gut microbiota; Proteobacteria, Firmicutes, and Actinobacteria in which several species among them belong to the lactic acid bacteria (LAB). In general, some species of LAB can be developed as potential probiotics due to their capability to produce bioactive compounds such as organic acid (lactic acid, acetate acid and formic acid), hydrogen peroxide $\left(\mathrm{H}_{2} \mathrm{O}_{2}\right)$, ethanol, enzymes, benzoate, antimicrobial peptides (AMPs), free fatty acid, and volatile compounds-that in a synergistic action work as broad-spectrum antimicrobials toward several pathogens. Several strains of LAB that living in symbiosis within the digestive tract of honey bees have been isolated, among them are quite promising to be developed as probiotics. Multiple studies have shown the inhibitory effect of LAB from honey bees against pathogenic microorganisms. Formic acid and lactic acid produced by symbiotic LAB could decrease the environmental $\mathrm{pH}$ of wounds, therefore prevent the growth of pathogenic microbes. Furthermore, the volatile compound produced by $\mathrm{LAB}$ is toxic, while $\mathrm{H}_{2} \mathrm{O}_{2}$ in small numbers is needed for optimal wound recovery. LAB capable of producing broad-spectrum antibacterial compounds such as Serratia marcescens, Eschericia coli, methicillin-resistant Staphylococcus aureus, Klebsiella aerogenes, Salmonella typhi, Pseudomonas spp., Klebsiella spp., Proteus spp., S. aureus, and Bacillus subtilis. Additionally, LAB possess antioxidant activity and to adhere the epithelial cells. This paper aimed to discuss varieties of LAB from the digestive tract of honey bees and their potential as probiotics that could benefit healthcare.
\end{abstract}

Keywords: honey bees, lactic acid bacteria, gut, probiotic

\section{INTRODUCTION}

Honey bees (Apis spp.) are honey-producing insects that classified into subfamily Apinae of the family Apidae [1]. There are nine species from the genus Apis that are recognized worldwide [2], whereas in Indonesia there has been discovered at least five honey bees species namely Apis andreniformis, A. nigrocincta, A. dorsata, A. koschevnikovi, and A. cerana [3].

As social insects, honey bees possess unique gut microbiota community. There are three main phyla that dominate the honey bees gut microbiota: Proteobacteria (Gilliamella, Parasaccharibacter and Frischella), Actinobacteria (Bifidobacterium) and Firmicutes (Lactobacillus sp. Firm-4 and Firm-5), in which several species among them belong to the lactic acid bacteria (LAB) [4]. LAB belong to gram-positive bacteria, they are non-spore forming cocci or coccobacilli, anaerob or facultative aerobe rods that produce organic acids, such as lactic acid which is the main fermentation result of carbohydrate metabolism [5]. LAB synergistically within the gastrointestinal tract of humans, insects, and other animals $[6,7]$. Some species of LAB can be developed as potential probiotics. This is due to their capability to produce bioactive compounds such as lactic acid, acetate acid, and formic acid, hydrogen peroxide $\left(\mathrm{H}_{2} \mathrm{O}_{2}\right)$, ethanol, enzymes, benzoate, antimicrobial peptides (AMPs), free fatty acid, and volatile compounds that in a synergistic action work as broad-spectrum antimicrobials toward several pathogens [8]. Among several isolated symbiotic LAB strains of the honey bees digestive tract, it is found that some of them showed potential results to be developed as probiotics $[8,9]$. The objective of this review was to discuss the potential of various LAB found in the honey bees gut as probiotics that beneficial for healthcare. 


\subsection{Materials and Methods}

This paper was incorporated by using a library research method. The data were collected by analysing several books, both printed and electronic documents, and other sources or information related to the research. In this paper we assembled premises from several literatures that discuss the lactic acid bacteria from honey bees digestive tract. After that we examined several studies regarding the potential probiotic of LAB from honey bees digestive tract. The conclusion of assumptions was then taken subjectively.

\subsection{Our Contribution}

This paper presents varieties of LAB from the gut of honeybees and their potential as probiotics that could benefit healthcare. By referring to this study which is supported by various references regarding the probiotic potential of LAB from honeybees gut, further research on this topic can be developed.

\subsection{Paper Structure}

The rest of the paper is organized as follows. Section 2 explains about the microbiota community in the honeybees gut; LAB that are specific to honeybees that have been isolated from honeybee guts of various species; and potential probiotic of LAB from honeybees gut. Finally, Section 4 concludes the paper and it is believed that further studies to assess the health-promoting activity of probiotic bacteria isolated from honeybee's digestive tract are required.

\section{RESULTS AND DISCUSSION}

\subsection{The Honey Bees Gut Microbiota}

Among the microbiota community in the honey bees gut, there are nine dominating bacterial species clusters. These clusters are specific to bees and can be transmitted by social interactions between bees [10]. There are five main bacteria groups in the honey bees gut community: Gram-negative bacteria group (Snodgrassella alvi and Gilliamella apicola), members of the phylum Proteobacteria $[10,11]$ to Gram-positive bacteria, Firmicutes (Lactobacillus Firm-4 and Lactobacillus Firm5 groups) [10], phylum Actinobacteria (Bifidobacterium asteroids) [10, 12], a small number of Proteobacteria species (Frischella perrara, Bartonella apis, Parasaccharibacter apiu, and a Gluconobacter-related species group designated Alpha2.1). Over millions of years, these bacteria together formed a specialized microbial community that have co-evolved and diversified with their bee hosts [10]. This microbiota community is very dynamic and adaptive since its existence is influenced by several factors such as nutrition, hive environment, social interaction, and the age of honey bees, whereas its composition follows seasonal patterns [4].

\subsection{Lactic Acid Bacteria Specific to Honey Bees}

The LAB that are specific to honey bees that have been isolated from various species of the honey bees gut can be seen in Table 1. The LAB species of the honey bees are all Gram-positive, facultative anaerobic bacteria that do not form spores, immotile, and produce lactic acid. The abundance of LAB species in honey bees varies depending on the season, their health, floral resources, and their contact with older bees of the colony $[4,15]$. As the most dominant species among the sub-species Apis [19], L.

Table 1 The lactic acid bacteria honey bees gut

\begin{tabular}{|l|l|c|}
\hline \multicolumn{1}{|c|}{ Honey bee species } & \multicolumn{1}{c|}{ Lactic acid bacteria } & References \\
\hline Apis mellifera & $\begin{array}{l}\text { Lactobacillus kunkeei, Fructobacillus } \\
\text { fructosus, } \text {. johnsonii, Enterococcus } \\
\text { faecium, Micrococcus }\end{array}$ & {$[13-16]$} \\
\hline A. cerana indica & $\begin{array}{l}\text { Lactobacillus, L. plantarum, Lactococcus, } \\
\text { Enterococcus, Micrococcus, } \\
\text { Streptococcus, Pediococcus, Leuconostoc }\end{array}$ & {$[15,17]$} \\
\hline A. dorsata & $\begin{array}{l}\text { Lactobacillus, L. kunkeei, L. vermiorm, } \\
\text { Lactococcus lactis }\end{array}$ & {$[6,15]$} \\
\hline A. florea & $\begin{array}{l}\text { L. kunkeei, L. plantarum, } \\
\text { L. apis, Micrococcus }\end{array}$ & {$[7,15]$} \\
\hline A. nigrocincta & $\begin{array}{l}\text { Bifidobacterium, Enterococcus, } \\
\text { Fructobacillus, Lactobacillus, } \\
\text { Lactococcus, Leuconostoc, Vagococcus }\end{array}$ & {$[18]$} \\
\hline
\end{tabular}


kunkeei was abundant during spring and summer but almost absent during winter [4]. A healthy A. mellifera adults were collected from five geographically different locations of Apulia, Italy and Lactobacillus kunkeei and $F$. fructosus were successfully isolated from its digestive tract with the range of $69 \%$ and $31 \%$, respectively. Almost all of the isolates were fructophilic lactic acid bacteria (FLAB) which consumed fructose as the main source of carbohydrate [14]. Other studies of the worker bee $A$. mellifera gut showed eight strains of Lactobacillus spp. and five strains of Enterococcus spp., which according to 16S rRNA sequencing AJ5, IG9, A15, and CRL1647 strain had 99\% similarity with L. johnsonii, whereas SM21 showed 99\% similarity with Enterococcus faecium [13]. From the abdomen of $A$. dorsata bee in Malaysia, it was discovered that there were 34 strains that produced three different rRNA sequences from 15 different strains of Lactobacillus, consisting of L. kunkeei (56\%), other sequence related to other Lactobacillus sp. (38\%) and $L$. vermiform (6\%) [6].

L. kunkeei, L. plantarum, and L. apis were found from the gastrointestinal tract of the Asian dwarf honey bee ( $A$. florea) which was distributed from different regions of Iran [7]. From the A. Nigrocincta gut in the urban areas of Manado, Indonesia, Bifidobacterium, Enterococcus, Fructobacillus, Lactobacillus, Lactococcus, Leuconostoc, and Vagococcus were found [18]. Bifidobacterium along with other rare species namely Leoconostoc and Vagococcus were only found in Lombogia's study.

\subsection{Probiotic Potential of Lactic Acid Bacteria from Honey Bees Gut}

According to the Food and Agriculture Organization (FAO) and World Health Organization (WHO), probiotics are living microorganisms, which can provide health benefit on the host when it was given in adequate amount [20]. Probiotic microorganisms are commonly obtained from conventional sources such as dairy foods. On the other hand, the use of probiotic from unconventional sources such as non-intestinal sources, non-dairy fermented food products, and various parts of digestive tract from animals are potentially to increase [21].
Several LAB strains from the honey bee gut have the potential as probiotics that beneficial for health [19]. Various microbiota LAB in honey bees are thought to be the first line of defense toward potential pathogens against its host. One of the bioactive components in the LAB that is isolated from the honey bee gut is antimicrobial peptide (AMP), a very important part of the immune system which is also a promising alternative to the current antibiotic treatment or prevention of microbial infection [22,23]. AMPs belong to a diverse group of LAB from digestive tract of honey bees that could be seen in Table 2 . Helveticin J, bacteriolysin, alivaricin, enterolysin A, and thermophilin A are AMPs that can be found in several strains of Lactobacillus isolated from A. mellifera [24, 25]. However, bacteriolysin is also found in Bifidobacterium strain [24]. Meanwhile bacteriocin and bacteriocin-like compounds are found in strains of Enteroccocus [13, 26]. These various AMPs enable LAB from honey bees to act as probiotics to inhibit pathogenic bacteria. The inhibitory effect of LAB towards bacterial pathogens have been proved in several studies $[8,13,16,27-30]$ as shown in Table 3.

Lactobacillus johnsonii CRL164, AJ5 and IG9 produced a significant amount of lactic acid ranged from 177 to 275 $\mathrm{mM}$. In vitro, these strains are capable of inhibiting various human food-borne pathogens and the American foulbrood causal agent, Paenibacillus larvae. Furthermore, E. faecium is thought to have an anti-lysteria effect [13]. Lactobacillus apis sp. nov., which was isolated from the abdomen of A. mellifera, could inhibit Paenibacillus larvae subsp. Larvae and Melissococcus plutonius (causal agent of European foulbrood) in in vitro manner [28]. A study of thirteen Lactobacillus strains from A. mellifera in severe wounds by methicillin-resistant Staphylococcus aureus (MRSA), vancomycin-resistant Enterococcus (VRE) and Pseudomonas aeruginosa showed result of strong and synergic antimicrobial activities for each symbiont against the pathogens. Its mode of action is through elucidating the production of active compounds such as organic acid, phosphate acid and, lactic acid as well as other volatile compounds and hydrogen peroxide $\left(\mathrm{H}_{2} \mathrm{O}_{2}\right)$. Organic acid reduces the $\mathrm{pH}$ and will create an unfavorable environment to promote wound development. Formic and lactic acid produced by LAB symbiont

Table 2 The lactic acid bacteria from honey bees's digestive tract and their antimicrobial peptides

\begin{tabular}{|l|l|l|l|}
\hline Honey bee species & Antimicrobial peptides & Lactic acid bacteria & References \\
\hline Aphis mellifera & Helveticin J & Lactobacillus Bma5N & {$[24]$} \\
\hline A. mellifera & Bacteriolysin & $\begin{array}{l}\text { L. Fhon13N, Hon2N, L. } \\
\text { kunkeeiFhon2N, } \\
\text { Bifidobacterium } \\
\text { Hma3N }\end{array}$ & {$[24]$} \\
\hline A. mellifera & $\begin{array}{l}\text { L. salivarius A3iob, L. [. } \\
\text { johnsonii CRL1647 }\end{array}$ & [25] \\
\hline A. mellifera & Bacteriocin & Enterococcus avium & {$[26]$} \\
\hline A. mellifera & Bacteriocin-like compounds & E. faecium & {$[13]$} \\
\hline
\end{tabular}


Table 3 In vitro studies of antimicrobial activities against pathogens by LAB isolated from honey bees gut

\begin{tabular}{|l|l|l|}
\hline \multicolumn{1}{|c|}{ Lactic acid bacteria species } & \multicolumn{1}{|c|}{ Target pathogen/effect } & References \\
\hline Lactobacillus johnsonii & $\begin{array}{l}\text { Staphylococcus aureus, Escherichia coli, Bacillus cereus, } \\
\text { Paenibacillus larvae, Listeria monocytogenes }\end{array}$ & {$[13]$} \\
\hline Enterococcus faecium & L. monocytogenes & {$[13]$} \\
\hline $\begin{array}{l}\text { L. kunkeei Fhon2, L. kunkeei } \\
\text { Yubipro, L. kunkeei Lahm }\end{array}$ & $\begin{array}{l}\text { Serratia marcescens, E.coli, Klebsiella aerogenes, P. aeruginosa, } \\
\text { S. aureus, MRSA }\end{array}$ & {$[27]$} \\
\hline Lactobacillus & $\begin{array}{l}\text { Methicillin-resistant Staphylococcus aureus (MRSA), } \\
\text { Pseudomonas aeruginosa, vancomycin-resistant Enterococcus } \\
\text { (VRE) }\end{array}$ & {$[8]$} \\
\hline L. apis sp. nov & Paenibacillus larvae subsp. larvae, Melissococcus plutonius & {$[28]$} \\
\hline $\begin{array}{l}\text { L. gasseri, L. kunkeei, L. } \\
\text { amylovorus, L. fructivorans }\end{array}$ & Paenibacillus & {$[29]$} \\
\hline F. fructosus & $\begin{array}{l}\text { Methicillin-resistant Staphylococcus aureus (MRSA), } \\
\text { Pseudomonas aeruginosa }\end{array}$ & {$[16]$} \\
\hline
\end{tabular}

decrease the $\mathrm{pH}$ of the wound environment. Moreover, the volatile compounds produced by the LAB are toxic. Small amounts of $\mathrm{H}_{2} \mathrm{O}_{2}$ are needed for optimal wound healing [8]. A review that was made based on several studies revealed that L. kunkeei Fhon2, L. kunkeei Lahm, and L. kunkeei Yubipro that were isolated from the digestive tract of honey bees, are the 3 types of LAB that could potentially produce bioactive compounds with antibioticlike activity.

Lactic acid bacteria are capable of producing broadspectrum antibacterial compounds against various pathogenic microbes such as $S$. marcescens, $P$. aeruginosa, K. aerogenes, E.coli, S. aureus and MRSA [27]. The antimicrobial evaluation activity of Lactobacillus spp. isolated from A. mellifera showed that the best antimicrobial effect of Lactobacillus spp. ( $L$. fructivorans, L. amylovorus, L. gasseri, L. kunkeei) was against Paenibacillus larvae that present in the digestive tract of L. gasseri supernatant. A lower level of antimicrobial activity was detected in $L$. kunkeei supernatant. The strongest antimocrobial activity against larva Paenibacillus CCM 4438 was detected in L. gasseri and $L$. amylovorus, while the lowest was detected in $L$. fructivorans [29]. A study of LAB isolates from the gut of A. mellifera showed that $F$. fructosus (SHGH-1, SHGH-4, and SHGH-14) have the highest inhibition zone against Pseudomonas aeruginosa then $F$. fructosus (SHGH-11) against Staphylococcus aureus (MRSA) [16]. There are 6 isolates from the gut of $A$. cerana indica that have antimicrobial activity against pathogen such as Salmonella typhi, S. paratyphi A, E. coli, Klebsiella spp., Pseudomonas spp., Proteus spp., S. aureus, and Bacillus subtilis [30]. All of these studies revealed that LAB have the potential sources of antibacterial substances that are effective against pathogenic Gram negative and Gram positive bacteria. Besides having antimicrobial potential, Lactobacillus has the best antioxidant effect as proven by the discovery of $L$. plantarum $\mathrm{H} 28$, and L. plantarum $\mathrm{H} 24$ from the digestive tract of honey bees [31].

\section{CONCLUSION}

There are various studies found that honey bees have a unique source of microbiota in their digestive systems. They are consist of three main phylum namely Proteobacteria, Firmicutes and Actinobacteria, which some of its species are classified as LAB. LAB microbiota isolated from the digestive tract of honey bees potential as probiotics, have the antioxidant activity as well as the ability to inhibit pathogens. This ability by bioactive compounds such as AMPs and organic acid that contained in LAB. Further studies are required to assess the healthpromoting activity of probiotic bacteria isolated from honey bee digestive tract.

\section{ACKNOWLEDGMENT}

This research was supported by Entomology Study Program, Postgraduate Program, Sam Ratulangi University and Department of Biology, Faculty of Mathematics and Natural Sciences, Sam Ratulangi University, Department of Dermatology and Venereology, Faculty of Medicine, Sam Ratulangi University, North Sulawesi, Indonesia

\section{REFERENCES}

[1] A. Rattanawannee, C. Chanchao, Bee diversity in Thailand and the applications of bee products, changing diversity environment. In Tech, Bangkok, Thailand, 2011. 
Orbales ord. nov., a sister taxon to the order 'Enterobacteriales' of the Gammaproteobacteria, Int J Syst Evol Microbiol 63 (2013) 2008-2018. DOI: https://doi.org/10.1099/ijs.0.044875-0

[3] S. Hadisoesilo, The diversity of indigenous honey bee species of Indonesia, Biodiversitas 2(1) (2001) 123-128.

DOI:https://doi.org/10.13057/biodiv/d020107.

[4] S. Lamei, The effect of honeybee-specific lactic acid bacteria on American foulbrood disease of honeybees Lund: Lund University, Faculty of Medicine, 2018.

[5] E.J. Quinto, P. Jimenez, I. Caro, J. Tejero, J. Mateo, T. Girbes, Probiotic lactic acid bacteria: a review, Food and Nutrition Sciences, 5 (2014) 1765-1775.

[6] N. Tajabadi, M.Y. Mardan, A. Manap, M. Shumaimi, A. Meimandipour, L. Nateghi, Detection and identification of Lactobacillus bacteria found in the honey stomach of the giant honeybee Apis dorsata, Apidologie 42 (2011) 642649. DOI: https://doi.org/10.1007/s13592-0110069-X

[7] S. Parichehreh, G. Tahmasbi, A. Sarafrazi, S. Imani, N. Tajabadi. Isolation and identification of Lactobacillus bacteria found in the gastrointestinal tract of the dwarf honey bee, Apis florea Fabricius, 1973 (Hymenoptera: Apidae), Apidologie 49 (2018) 430-438. DOI: https://doi.org/10.1007/s13592-018-0569-z

[8] T.C. Olofsson, E. Butler, P. Markowicz, C. Lindholm, L. Larsson, A. Vasquez, Lactic acid bacterial symbionts in honeybees - an unknown key to honey's antimicrobial and therapeutic activities, Int Wound $J 13$ (2016) 668-679. DOI:https:// doi.org/10.1111/iwj.12345

[9] A. Berasategui, S. Shukla, H. Salem, M. Kaltenpoth, Potential applications of insect symbionts in biotechnology, Appl Microbiol Biotechnol $\quad 100 \quad$ (2016) 1567-157. DOI:https://doi.org/ 10.1007/s00253-015-7186-9

[10] W.K. Kwong, N. A. Moran, Gut microbial communities of social bees, Nat Rev Microbiol 14(6) (2016) 374-384. DOI: https://doi.org/ doi:10.1038/nrmicro.2016.43

[11] W. K. Kwong, N. A. Moran, Cultivation and characterization of the gut symbionts of honey bees and bumble bees: description of Snodgrassella alvi gen. nov., sp. nov., a member of the family Neisseriaceae of the Betaproteobacteria, and Gilliamella apicola gen. nov., sp. nov., a member of Orbaceae fam. nov.,
[12] F. Bottacini, C. Milani, F. Turroni, B. Sanchez, E. Foroni E, et al. Bifidobacterium asteroides PRL2011 Genome Analysis Reveals Clues for Colonization of the Insect Gut, PloS One 7 (2012) e44229. DOI: https://doi.org/10.1371/journal.pone.0044229

[13] M. C. Audisio, M. J. Torres, D. C. Sabaté, C. Ibarguren C, M. C. Apella, Properties of different lactic acid bacteria isolated from Apis mellifera $\mathrm{L}$. bee-gut, Microbiol. Res. 166(1) (2011) 1-13. DOI: https://doi.org/10.1016/j.micres.2010.01.003

[14] P. Filannino, R. Di Cagno, R. Addante, E. Pontonio, M. Gobbetti, Metabolism of fructophilic lactic acid bacteria isolated from the Apis mellifera L. bee gut: phenolic acids as external electron acceptors, Appl. Environ. Microbiol 82(23) (2016) 6899-6911. DOI: https://doi.org/10.1128/AEM.02194-16

[15] M. Mathialagan, Y. S. J. T. Edward, P. M. M. David, M. Senthilkumar, M. R. Srinivasan, S. Mohankumar S, Isolation, characterization and identification of probiotic lactic acid bacteria (LAB) from honey bees, Int. J. Curr. Microbiol. App. Sci 7 (4) (2018) 894-906. DOI: https://doi.org/10.20546/ijcmas.2018.704.096

[16] S. M. Salman, G. Saleh, Fructophilic lactic acid bacteria symbionts in honeybees - a key role to antimicrobial activities, IOSR Journal of Pharmacy and Biological Sciences 13 (1) (2018) 58-62. DOI: https://doi.org/10.9790/30081301055862

[17] C. C. Honey, T. R. Keerthi, Probiotic potency of Lactobacillus plantarum KX519413 and Microbiol. Lett 365(4) (2018). DOI: https://doi.org/10.1093/femsle/fnx285

[18] C. A. Lombogia, M. Tulung, J. Posangi, T. E. Tallei, Gut-associated lactic acid bacteria (LAB) in Apis nigrocincta (Smith), 2019. In press.

[19] A. Vásquez, E. Forsgren, I. Fries, Symbionts as major modulators of insect health: lactic acid bacteria and honeybees, PloS one 7(3) (2012) e33188.

DOI: HTTPS://doi.org/10.1371/journal.pone.0033188

[20] Food and Agriculture Organization (FAO). World Health Organization (WHO) Report of a joint FAO/WHO expert consultation on evaluation of KX519414 isolated from honey bee gut, FEMS 
health and nutritional properties of probiotics in food including powder milk with live lactic acid bacteria. Córdoba, Argentina, 2001.

[21] P. Sornplang, S. Piyadeatsoontorn, Probiotic isolates from unconventional sources: a review, Journal of Animal Science and Technology 58 (2016) 26. DOI: https://doi.org/ 10.1186/s40781016-0108-2

[22] R. A. Ilyasov, L. R. Gaifullina, E. S. Saltykova, A. V. Poskryakov, A. G. Nikolenko, Review of the expression of antimicrobial peptide defensin in honey bees Apis mellifera 1. Journal of Apicultural Science 56(1) (2012). DOI: https://doi.org/10.2478/v10289-012-0013-y

[23] J. Danihlík, K. Aronstein, M. Petřivalský, Antimicrobial peptides: A key component of honey bee innate immunity, Journal of Apicultural Research, 2016. DOI: https://doi.org/ 10.1080/00218839.2015.1109919

[24] E. Butler, M. Alsterfjord, T. C. Olofsson, C. Karlsson, J. Malmström, A. Vásquez, Proteins of novel lactic acid bacteria from Apis mellifera: an insight into the production of known extra-cellular proteins during microbial stress, BMC Microbiol. $13 \quad$ (1) $235 \quad$ (2013). https://doi.org/10.1186/1471-2180-13-235

[25] M. C. Audisio, L. Albarracín, M. J. Torres, L. Saavedra, E. M. Hebert, J. Villena, Draft genome sequences of Lactobacillus salivarius A3iob and Lactobacillus johnsonii CRL1647, novel potential probiotic strains for honeybees (Apis mellifera L.), Microbiol Resour Announc. 7(6) (2018) e0097518. DOI: https://doi.org/10.1128/MRA .00975-18

[26] M. C. Audisio, H. R. Terzolo, and M. C. Apella, Bacteriocin from honeybee beebread Enterococcus avium, active against Listeria monocytogenes, Applied and Environmental Microbiology 71(6) (2005) 3373-3375. DOI: https://doi.org/10.1128/AEM.71.6.33733375.2005

[27] N. A. Sandi, S. I. O. Salasia, Alternative antibiotics source from symbiont of lactid acid bacteria inside stomach of honeybees (Apis mellifera and Apis dorsata) against multiresistant antibiotics pathogenic bacteria, Res J. Microbiol. $11 \quad$ (2-3) (2016) 93-100. DOI: https://doi.org/10.3923/jm.2016.93.100

[28] J. Killer, S. Dubna, I. Sedlacek, P. Svec, Lactobacillus apis sp. nov., from the stomach of honeybees (Apis mellifera), having an in vitro inhibitory effect on the causative agents of American and European foulbrood, International
Journal of Systematic and Evolutionary Microbiology 64 (2014) 152-157. DOI: https://doi.org/ 10.1099/ijs.0.053033-0

[29] M. Kacaniova, J. Gasper, M. Terentjeva, S. Kunova, M. Kluz, C. Puchalski, Antibacterial activity of bees gut Lactobacilli against Paenibacillus Larvae in vitro, Advanced research in life sciences 2 (1) (2018) 7-10. DOI; https://doi.org/10.1515/arls-2018-0020

[30] Keerthi TR, Jacob AA and Honey C, Honey bee gut flora as a source of LAB (Lactic Acid Bacteria) with probiotic capabilities, The Journal of Food Technology Photon 105 (2013) 126-134.

[31] Kenfack CHM, Ngoufack FZ, Kaktcham PM, Wang YR, Zhu $\mathrm{T}$ and Yin L, Safety and antioxidant properties of five probiotic Lactobacillus plantarum strains isolated from the digestive tract of honey bees, American Journal of Microbiological Research 6 (1) (2018) 1-8. DOI: https://doi.org/10.12691/ajmr-6-1-1 